\title{
Knowledge Transfer Across Types of Assignments: Case study of an International Oil Company
}

\author{
Amal. M. Jawad (Corresponding author) \\ The Business School, Edinburgh Napier University, \\ 219 Colinton Rd, Edinburgh EH14 1DJ, United Kingdom \\ E-mail: amal.jawad@napier.ac.uk
}

Received: Aug. 30, 2020 Accepted: Sept. 28, 2020 Online published: Oct. 16, 2020

doi:10.5296/ijhrs.v10i4.17840ＵRL: https://doi.org/10.5296/ijhrs.v10i4.17840

\begin{abstract}
The principal objective of this paper is to explore how using different sorts of international assignments (short-term expatriation, long-term expatriation, short-term inpatriation) enable the headquarters (HQ) and ancillary branches to transfer an assortment of knowledge types (procedural, declarative, axiomatic, and relational knowledge) from the HQ to their ancillaries, through the period of assignment. The current study used a qualitative approach based on the data collection strategy of semi-structured interviews with 20 partakers with standings of international assignment (IA). The content analysis methodology was managed to analyze and codify the interviews. The findings reveal that every single kind of assignment acts as a special knowledge transfer situation. The principal benefaction of our study is that it delivered a more precise understanding of international assignments as knowledge transfer situations than any research in precedence. While the contributions of this study have been salient, certain limitations pave the way for extensive research possibilities. To begin with, this paper lays emphasis on a large organisation in the Oil and Gas sector in three countries, UK (the HQ), Oman and UAE, which limits generalization of the findings. The paper reviews the implications of selecting IA to transfer the various types of knowledge. We achieve this by distinguishing the knowledge convey role of international assignments across different types of assignments, types of knowledge, and the direction and timing of knowledge transfer through or following the international assignment. First this paper is necessary to analyze the success of knowledge transfer and IA and ascertain their application. To the best of our knowledge, this research one of the rare studies that include the engineer's perspective in the global Oil and Gas sector. This umbrella approach aids in better understanding IA and knowledge transfer.
\end{abstract}

Keywords: inpatriation, knowledge types, expatriation, knowledge transfer 


\section{Introduction}

Multinational companies (MNCs) rely on various types of international assignments (Collings, et al., 2010). Recently, the numbers of employees in international organisations have increased, affecting the management of organisations on worldwide, regional, and local levels (Mockaitis, Zander and DeCieri, 2018). IA can enhance assignees' careers (Brewster and Suutari, 2005, Salamin and Hanappi, 2014) and possibly enable them to promote to higher management positions in MNCs (Cao et al., 2012, Salamin and Hanappi, 2014). But the conclusion has been reached at under the presumption that the various types of international assignments (IA) are evenly appropriate for transferring different types of knowledge among HQ and ancillaries, which leaves room for ambiguity and inaccuracy. (Edström \& Galbraith, 1977a, 1977b; Harzing et al., 2019), because MNCs operate in multiple institutional backgrounds at the same time, and the differences among these institutional backgrounds might create all sorts of misconceptions among employees on international assignments. Further, there are legitimacy issues accompanying workforce relocation to a 'new' country, and challenges for transfers of knowledge and the performance of organisational routines (Zaheer, 1995; Reiche, 2012). These challenges are even more serious for MNCs and their staff. The knowledge transfer among the HQ and ancillaries plays a critical role in a global organisation (Harzing et al., 2016). Past research has indicated the contribution of international assignments in helping knowledge transfer among headquarters and ancillaries (Edström \& Galbraith, 1977), based on the role knowledge-based view of the firm (Kogut \& Zander, 1993) advancing this role (Bonache \& Brewster, 2001).

Moreover, academic studies have demonstrated that long-term (Fang et al. 2010) and short-term (Salleh and Nankervis, 2015) expatriation and inpatriation (Harzing et al., 2016; Collings et al., 2010) are significant knowledge transfer situations for international corporations. Based on McNulty and Brewster's (2017) categorization, we will explore how three specific types of IAs assisted in transferring knowledge from and to the Oman subsidiary over the period of engineers' assignments to the UK headquarters. By examining this HQ-subsidiary connection, we could perceive how a knowledge transfer stream develops initially among an HQ and a subsidiary. Yet, is not easy to transfer some types of knowledge (Lagerström \& Andersson, 2003). The of the (IA) might be differ in direction of the transfer the knowledge, and the precise timing of the knowledge transfer among the HQ and ancillaries, and the type of knowledge (Harzing et al., 2016).

The present research makes three principal contributions. First, the study concentrated mainly on LT expatriation (Choi \& Johanson, 2012). Salleh \& Koh (2013) reported on short-term (ST) expatriation and Reiche (2011) mentioned inpatriation; however, the area remains hardly explored. Also, this study thus broadens the compositions of (IAs) by distinguishing among and systematically contrasting headquarters' foreign subsidiary knowledge transfer models of ST expatriation, LT expatriation and ST inpatriation. Secondly, we disagree with the tacit postulate in past (IAs) research that knowledge is a solid concept. Precisely, the study distinguishes among types of knowledge transferred among headquarters and foreign ancillaries with emphasis on declarative, procedural, axiomatic, and relational knowledge. Third, we explicitly explore whether the knowledge transfer takes place through or following 
the assignment, as opposed to the preliminary research that finds basis in the extent and direction of knowledge transfer through international assignments. The current research procedure provides new evidence on why different types of (IA) are integral rather than distinguished ways of transferring knowledge, and the reasons why it is important that MNCs use variety of (IAs) to realistically gathering their knowledge transfer requirements. The primary accord of our research is therefore to offer a greater interpretation of (IAs) as knowledge transfer situations than previous studies have provided, by exploring how various types of IA enable the transfer of various types of knowledge. We realize this by distinguish the knowledge transfer function of (IAs) by the type of assignment, type of knowledge, and the direction and timing of knowledge transfer. Similarly, Collings and Isichei (2017) explore the extent to which the utilization of (IAs) in organizations and the circumstances that are conducive for individuals to accept or refuse global positions have changed significantly over recent years. This has important involvement for MNCs in terms of the accessibility and readiness of employees to start their roles globally. Shaffer and Harrison (1998) studied a sample of 452 expatriates living in 45 countries and proposed a model guideline on how they quit their assignments. The study found that organisational commitment and job satisfaction were impacted by expatriate withdrawal from their task. Further, Salamin \& Hanappi (2009) studied female expatriates, exploring data from 151 known journal articles published since 1975. The authors' emphasis was on studying the individual level, and they found the research follows a home-host country process. Moreover, Mockaitis et al., (2018) argue that international assignments can develop international competence in expatriates, and greater benefits can be accomplished by engaging individuals in rotating global team assignments.

The study adopts an in-depth qualitative method: we collected 20 semi-structured interviews with professional engineers that allowed the researcher to differentiate among four types of knowledge - declarative, procedural, axiomatic, and relational knowledge (Anderson, 1976; Winograd, 1975, and Squire, 1987), and to get in depth how these various knowledge are transferred by various sort of (IAs) in diverse ways in and out the headquarter and at various times through of time or following the assignment. Thus, various types of IA - for example, long-term (LT) expatriation, short-term (ST) expatriation and ST inpatriation - assist in transferring knowledge from the headquarters in the UK to the Oman subsidiary. Furthermore, we demonstrate that the combination of IA types and the arrangement in which different assignments are used are additional significant factors to consider when designing international programmes to transfer knowledge among HQ and foreign ancillaries.

The next section explains the various types of knowledge and various types of (IAS), describes the methodology, then summarises the findings and discusses the theoretical implications. Finally, the study limitations and future research will be described.

\section{Literature Review}

Complex learning takes longer and tends to be a more complicated process than the associative process. There are different definitions and typologies to the knowledge from many scholars such as (Antal, 2000; Anderson, 1995; Sackmann, 1992; Sanchez \& Heene, 1996). Complex knowledge can be divided to the two kinds: declarative knowledge and 
procedural knowledge. First, declarative knowledge is described as knowledge of detail or "knowing that"; Declarative knowledge is used by the individual, is descriptive and symbolizes concepts, ideas, principles, schemas, and theories (Ohlsson, 1993; 1996). A person's declarative knowledge involves concepts such as solving a problem without assistance of the specific occupation the individual assumes. Procedural knowledge, on the other hand, is "knowing how" (Anderson, 1976; Winograd, 1975): it is prescriptive and has specific uses. For instance, this type of knowledge indicates how to do something, such as solve a scientific problem. It entails making connections among situations, goals, and actions and is mainly tacit knowledge (Nonaka, 1994). Additionally, the axiomatic knowledge, "Knowing why", can be defined as theories on (Sackmann, 1992. Lastly, relational knowledge describes "who knows what" or "who knows how to do what" in the firm (Cohen and Levinthal (1990). MNCs face the challenge of developing social capital through the network of employees' relationships (Reiche, Harzing, \& Kraimer, 2009).

The four key types of knowledge explained above help the MNCs to transfer knowledge among HQ and foreign ancillaries (Kogut et al., 1993), which is facilitated by international assignments (Fang et al., 2010). LT expatriation take duration between one to five years, whereby the expert's sent from the headquarter to a subsidiary (McNulty and roaster, 2017), has received more attention from researchers than the ST assignment. Also, LT expatriation can accomplish several tasks, from knowledge transfer, employment and hiring, and managerial training and development, in additional to organisational monitoring and settlement (Edström \& Galbraith, 1977; Harzing, 2001a, 2001b). Different from past studies, expatriates not only complete international assignments (Black, Gregersen \& Mendenhall, 1992; Schuler et al., 1993) and act as key bridges (Barner-Rasmussen et al., 2014), but furthermore, are considered as the foundation of institutional work for both the host and home countries. Basically, the expatriation helps to transfer knowledge among two functions, HQ and ancillaries (Harzing, 2001b; Hocking, Brown, \& Harzing, 2004). Initially, tacit knowledge exists in the individual opinion, however, establishes and transferred to other through behaviors and perception (Nonaka and Takeuchi, 1995). This indicates that communication is required to transfer knowledge among HQ and foreign ancillaries (Kogut \& Zander, 1993), which IA facilitates (Reiche, 2011, Fang et al., (2010). Furthermore, the LT expatriates have the technique to build trust and common cognitive basis, which enable to deliver of tacit knowledge (Mäkelä \& Brewster, 2009). Additionally, to transfer knowledge among units, LT expatriates furthermore assist in translating knowledge to form it easier to transfer the knowledge in new contexts (Johanson et al., 2012).

LT expatriation is recognized to have many benefits, but adjustment to a foreign environment and cross-cultural adaptation may be opposed effect the expatriates' performance. Pinto et al., (2012: 2297) pointed out that: 'Sociocultural adjustment and psychological well-being of expatriates and their families are preconditions for their success.' Additionally, some challenges exist such as insufficient chosen criteria or boring training (Haslberger et al., 2014). The successful transmit of knowledge through LT expatriation is contingent on the characteristics of the host country, the HCNs (home country natives) employed, and the expatriates; for instance, the motivation of HCNs and absorptive ability (Chang, Gong, \& 
Peng, 2012) and expatriates' encouragement and willingness to been in knowledge share (Lazarova \& Tarique, 2005). Furthermore, problems with cross-cultural adjustment and lack of experience in developing economies within the MNCs have raised attention (Haslberger et al., 2014). In addition, LT expatriates are attracted by might get great incentives, career progression, in addition to involve with different cultural and gain various experience (Al Ariss et al., 2014; Harvey \& Groutsis, 2012; Groutsis \& Arnold, 2012). However, it is considered one of the costliest resources in MNCs because the employees obtain more benefits and a plentiful incentive than the home country native (Sedlmayer, 2009), while this is not seen as globally true (McNulty, 2016). Recently more MNCs are keen to discover other types of IA, for instance short-term (ST) expatriation and inpatriation.

ST expatriation refers to assignments carried on for almost a year. (Suutari, Brewster, Riusala, \& Syrjäkari, 2013). ST assignments are less costly than LT expatriation and can reduce the problems of the transfer of relatives to foreign countries and career confusion. In contrast, it is difficult to build effective relationships with HCNs, and LT expatriates experience from an unsettle family life (Seppala et al., 2012) and frequent travel, resulting in lower levels of commitment and poor performance (Tahvanainen et al., 2005).

The motif of inpatriation includes send the domestic nationals to MNCs for short or long period of time (Harvey et al., 2000) for a year and a half at the most. Generally, inpatriates are assigned to headquarters in order to learn knowledge of the organisational culture, including norms and values and new skills, and disseminate to their home locale the embedded knowledge they have gained from the HQ (Harzing, 2004) on the one hand, and sometimes bring knowledge and opportunities to the subsidiary or problems to HQ further (Reiche et al., 2009). Inpatriates take on a twofold role in knowledge transfer (Reiche, 2006); usually, they distribute the knowledge of their HCNs to HQ employees, but sometimes they extend to transferring knowledge from headquarters to the foreign subsidiary on the accomplishment of their headquarter posting, such as that knowledge are important to the knowledge of inpatriates (Reiche, 2012). IHR managers should develop suitable training programs that will meet the unique needs of inpatriates at the HQ in place of posting expatriates to the subsidiary (Kühlmann and Hutchings, 2010). However, the assigned inpatriates also make an effort to adapt to their new context to build their social association with HQ (Reiche et al., 2009), changing the behaviors, mindsets, and attitudes of the employee to new cultures, which will be worthwhile when they're back to their own country. Meanwhile, inpatriates' assignments are short-term than LT expatriates by minimizing the expenses on relocation and repatriation. Furthermore, career opportunities often come to HCNs as they are motivated to become inpatriates (Reiche et al., 2011). However, inpatriates often come from developing economies around the world and HCNs may not give them the same level of respect and credibility as their expatriate peers (Reiche, 2011), and the headquarter employees may be unhelpful, because of their scare of losing control and authority (Harvey et al., 1999).

The current research focuses on knowledge transfer, but it is worth distinguishing the idea of knowledge transfer from the idea of knowledge learning and sharing. Knowledge sharing has been emphasized by various scholars (Mäkelä, 2007) and an overall literature review covers 
proof that scholars have considered these statments (Kumar \& Ganesh, 2009). Therefore, knowledge transfer involves an official systematic activity with particular ancillaries (Szulanski, 2000) and the progress of knowledge among other units and organisations (Szulanski et al., 2004), while knowledge sharing correlate to a large domain of knowledge-exchange activities in personal and organisational communications (Mäkelä, 2007), and is sometimes not planned or even deliberate (Mäkelä, 2007). Firstly, since we place emphasis on (IAs) as a technique used by headquarters to run and manage communication with ancillaries, we choose to denominate it as knowledge transfer. Secondly, knowledge transfer gives attention to the sender of the knowledge and the learning to emphasize the receiver. Therefore, the study concerns (IAs) as situations of knowledge transfer among the HQ and ancillaries.

\section{Methodology}

The study aims to explore the perspective of the professional engineers on how various types of (IAs) help transfer various types of knowledge among the HQ and their ancillaries for the MNCs. The study seeks to explore 1) how three specific types of (IAs) international assignments assist in transferring knowledge from and to the Oman subsidiary over the period of engineers' assignment at the UK headquarters, 2) how various types of IA enable the transfer of various types of knowledge, and 3) why different types of IA are complementary rather than distinct ways of transferring knowledge. The study adopts a qualitative research strategy. Additionally, the strategy sought to follow and differentiate knowledge transfer models through and following international assignments. Data gathering took place at two ancillaries of the MNC. The researcher used an inductive approach to generate theories from analysis of the data collected. Firstly, background was provided to define the research question and build the various types of knowledge and international assignments. Second, the research used the interviews to codify and identify the themes, which were then interpreted using content analysis.

\subsection{Case Study}

The research subject was a global Oil and Gas company headquartered in London. The company operates in 79 countries and has 70,100 employees around the world. Oil and Gas companies operate and maintain a network of geographically dispersed units that help create competitive advantages across various regions (Moeller, Harvey and Williams, 2010). The case study company management controls their international network on relocation of their employees among headquarters (HQ) and subsidiary units. Expatriation of HQ employees to ancillaries rose over the last decades of the twentieth century, but this growth has declined recently (Harzing, Pudelko \& Reiche, 2016; Reiche, 2006). The main reason for the change is that expatriation assignments of HQ managers often do not suffice for identifying the characteristics of foreign markets due to a lack of in-depth knowledge (Harzing et al., 2016). Effective knowledge movement among HQ and ancillaries is crucial. Typically, case studies are usually understood to offer a conservative scope to generalize. (Yin, 2009). The case study company did not provide generalizable findings; however, it has the potential to enhance the understanding of knowledge transfer throughout (IAs) in an HQ-foreign 
subsidiary unit. The author chose this case study because he received approval to obtain data from both HQ and a subsidiary in the Middle East (Oman).

\subsection{Data Collection}

The researcher conducted interviews and collected the data in two stages. The first stage started in HQ with six interviews of professional engineers (four interviews with senior management and two with junior engineers) in November 2019. The second phase of the interviews was with a subsidiary in Oman in August 2020 with 16 engineers. Moreover, the data collected enabled the researcher to manage and discuss knowledge transfer models through and following the (IAs). The author used the following criteria: (1) involved in (IAs), such as LT and ST expatriation and inpatriation, and HR manager mobility concerning policies at the subsidiary in the Oman office. (2) Ownership of knowledge concerning the topic, such as, how, what, when, from whom and to whom, various types of knowledge were transferred globally. (3) Face-to-face interviews in HQ and a subsidiary in Oman to gather the data from senior and junior engineers.

To safeguard systematic data collection, the author employed an interview with the framework of open-ended questions, with senior and junior engineers and HR managers. The interview was in a private room in an office of the subsidiary office with each of the individuals for a duration of fifty minutes to one hour and all the interviews were administered in English. For privacy reasons, the participants' names will not be mentioned. The researchers read the transcripts to verify emerging themes and ensure reliability. The coding theme was identified after the process of reading the interviews several times.

The coding frame was refined during the process of reading and re-reading the interviews. The researcher was able to identify themes relating to various international assignments and linked to knowledge transfer. Table 1 . shows the sample of participants in the study.

Table 1. Sample of participants

\begin{tabular}{|c|c|c|c|}
\hline Periods & Location & Interviewees & Job title \\
\hline \multicolumn{4}{|l|}{ Stage 1} \\
\hline $\begin{array}{l}\text { October } \\
18-25 / 201 \\
5 \text { interviews }\end{array}$ & $\begin{array}{l}\text { Subsidiary-Abu } \\
\text { Dhabi } \\
5 \text { interviews }\end{array}$ & $\begin{array}{l}\text { - LT expatriate- } 3 \text { interviews } \\
\text {-ST expatriate- } 2 \text { interviews } \\
\text {-inpatriate }\end{array}$ & $\begin{array}{l}\text { Vice present manager } \\
\text { IQ technical manager Middle } \\
\text { manager (engineer) } \\
\text { Senior engineer (technical) } \\
\text { Junior engineer } \\
\text { HR manager }\end{array}$ \\
\hline \multicolumn{4}{|l|}{ Stage 2} \\
\hline $\begin{array}{lll}\text { August } & 1- & 20 \\
-2019 & & \end{array}$ & $\begin{array}{l}\text { Subsidiary - Oman } \\
15 \text { interviews }\end{array}$ & $\begin{array}{l}\text { - LT expatriate } 3 \text { interviews } \\
\text { - ST expatriate } 2 \text { interviews } \\
\text {-inpatriate - } 10 \text { interviews }\end{array}$ & $\begin{array}{l}\text {-Senior engineers' specialists } \\
\text {-Junior engineers' } \\
\text {-Middle managers- Senior managers } \\
\text { engineers'- HR managers' }\end{array}$ \\
\hline
\end{tabular}

HCNs- Host country Nationals 


\subsection{Data Analysis}

The case study company has three types of (IAs) to and from the foreign subsidiary, such as LT and ST expatriation, and inpatriation programs. The researcher analysed the data through content analysis. First, codes were developed based on the themes in literature reviews (Miles \& Huberman, 1994), connected to knowledge transfer to all sort of assignment: declarative, procedural, axiomatic, and relational knowledge. Next, the researcher outlined theories connected to knowledge transfer to all sort assignment. The second level of analysis involved systematically comparing each of the codes with codes from previous research. The analysis was ended when all data had been assigned to a classification (type of international assignment) with a code pointed to the sort of knowledge transferred. The study found that the timing of knowledge transfer (throughout or following the assignment) and the direction of the knowledge transfer (from HQ to subsidiary unit or the opposite) provides a greater understanding of how different types of assignments produced different types of knowledge transfer in an HQ and Subsidiary unit.

\section{Findings}

Structuring of the finding's premises in the IA category: LT expatriation, ST expatriation, and ST inpatriation. The analysis was based on the way every kind of international assignment demonstrates particular attributes pertaining to the type of knowledge it helps transfer, the timing of the transfer, and the direction of the transfer. Table 2. summarizes the principal findings of the study, detailing how each type of IA exhibits features in relation to the type of knowledge it assists transferring, the timing of the transfer and the direction of the transfer.

Table 2. Study Findings

\begin{tabular}{|c|c|c|c|c|c|c|c|c|c|}
\hline \multicolumn{6}{|c|}{ Type of knowledge transferred from HQ to foreign subsidiary } & \multicolumn{4}{|c|}{$\begin{array}{l}\text { Type of knowledge transferred from foreign } \\
\text { subsidiary to HQ }\end{array}$} \\
\hline & & Declarative & Procedural & Axiomatic & Relational & Declarative & procedural & Axiomatic & Relational \\
\hline \multicolumn{10}{|c|}{$\begin{array}{l}\text { LT } \\
\text { Expatriation }\end{array}$} \\
\hline What & & & $\begin{array}{l}\text { Job } \\
\text { process }\end{array}$ & $\begin{array}{l}\text { Norms, } \\
\text { values, } \\
\text { expected } \\
\text { corporate } \\
\text { behavior }\end{array}$ & $\begin{array}{l}\text { Who to } \\
\text { contact at } \\
\text { HQ }\end{array}$ & & & & \\
\hline \multirow[t]{2}{*}{ When } & Through & & $X$ & $X$ & $X$ & n.a & n.a & n.a & n.a \\
\hline & Following & n.a & n.a & n.a & n.a & & & & \\
\hline \multicolumn{10}{|c|}{ ST Expatriation } \\
\hline What & & $\begin{array}{l}\text { Job } \\
\text { content }\end{array}$ & $\begin{array}{c}\text { Job } \\
\text { process }\end{array}$ & $\begin{array}{l}\text { Context } \\
\text { and } \\
\text { rationale } \\
\text { of the job } \\
\text { process }\end{array}$ & & & $\begin{array}{l}\text { Good } \\
\text { practices } \\
\text { (training of } \\
\text { new } \\
\text { recruits) }\end{array}$ & $\begin{array}{l}\text { HCNs } \\
\text { culture \& } \\
\text { sensitivity }\end{array}$ & \\
\hline
\end{tabular}




\section{Macrothink}

International Journal of Human Resource Studies

ISSN 2162-3058

2020, Vol. 10, No. 4

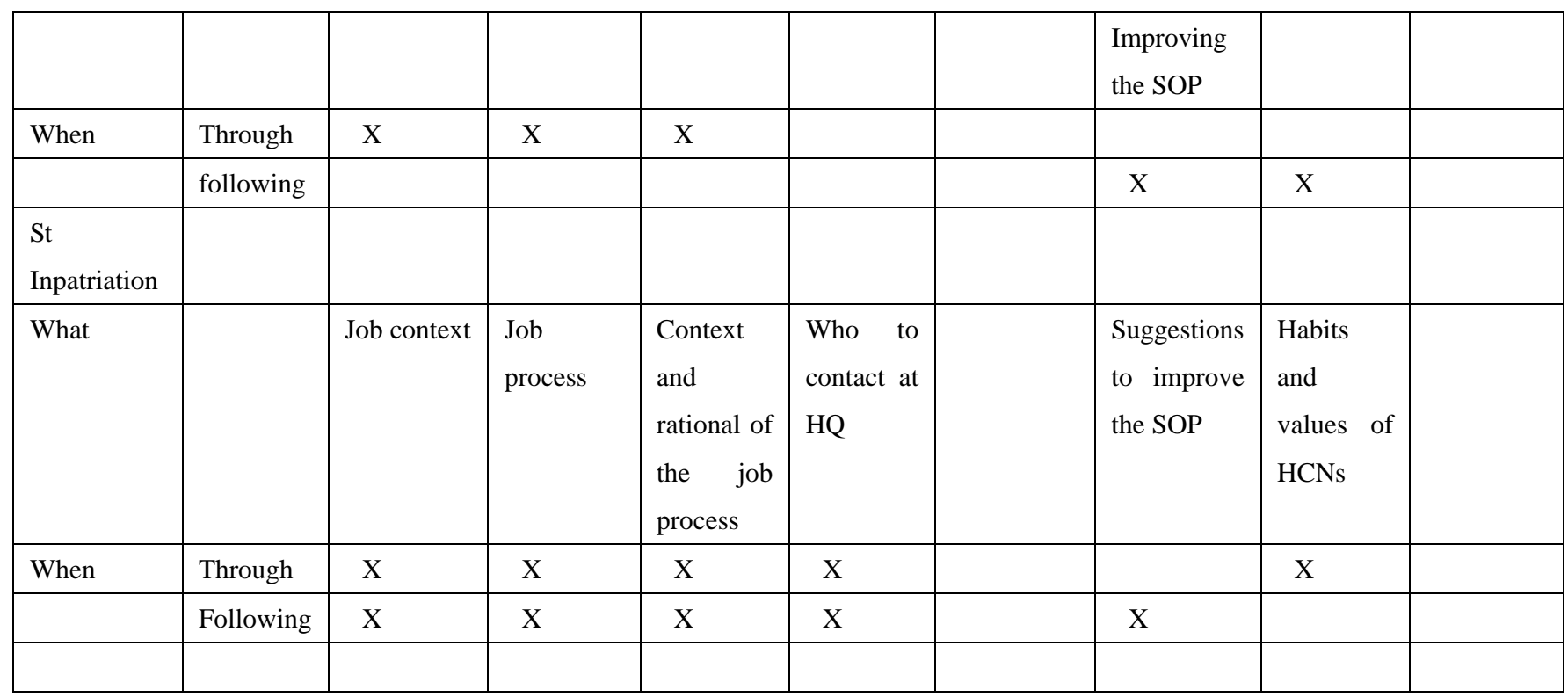

$\mathrm{HCN}=$ Host country national in Oman, $\mathrm{HQ}=$ Headquarter in $\mathrm{UK}, \mathrm{SOP}=$ Standard Operation Procedures, n.a $=$ LT expatriates had not yet returned from their assignments through our data collection.

\subsection{Knowledge Transfer Through LT Expatriation}

The LT assignment expatriates in the Oman unit were reported to be a fundamental pathway to ensure the work done in Oman and simplify knowledge transfer among Oman and UK HQ. Firstly, LT expatriates having the right process knowledge were transferred so that the criteria could be used, and tasks correctly implemented; the transfer may happen via the crucial trust such as the Standard Operating Procedures (SOP).

"A person training for a long-term assignment to get knowledge is going to get together with somebody who is mentoring him and transfer the information." (LT senior expatriate)

"My line manager was someone who was very supportive and intelligent, I would learn from him and come early every day just to do the work, and then try to be creative and take it further..." (ST junior inpatriate).

The transfer of axiomatic knowledge contains the HQ attitudes and value to carry out the work, which can be provided by the LT expatriation program. On the day-to-day work of individuals, the LT expatriates clarified to HCNs 'why' things were done along with the method by which they were to be done and why they were needed in practical terms. Initially, LT expatriates confirmed that the quite procedural knowledge was transferred so that the SOP (Standard Operating Procedures) would be used, and tasks would be accurately implemented.

"Well, I always say (HCNs) can manage how employees behave, because I don't believe the only things they provide is a buyer for the company, I think they provide massive value to the company, and explain to people what is behind the company values." (LT expatriate senior engineer)

The LT expatriates transferred some relational knowledge to enhance the efficiency of HCNs, 
such as whom to get in touch with at HQ when facing problems.

"Then you're reporting to someone in the UK, who is already in the head department, or contact them if you have any problem in a specific area." (LT expatriate senior HR manager)

\subsection{Knowledge Transfer Through ST Inpatriation}

Another increasing trend among MNCs is known as inpatriation, to transfer the knowledge gained during the international assignment to a subsidiary. In the HQ they pursued an intensive training program to transfer declarative knowledge regarding their ensuing career prospects. A senior manager at HQ explains the process:

"We send them, it depends on what type of responsibility engineers are going to take on in the future with their country. So, some of them we are sending for development. Some of them, to be in leadership positions... We send a group of people to the UK for around 18 months, they handle the tasks with ease, they have time to discuss what is behind the operations with their coach, they learn the SOPs (standard Operating Procedures) initially, then they learn from the coach...." (HQ subject matter senior engineer)

The researcher focused on the transfer of knowledge and on understanding the job role of employees who are sent on extended work assignments (i.e., expatriates and inpatriates) and the experiences of those individuals when they return home (i.e., repatriates) (Reiche, 2012). For example, classroom training at headquarters must be conducted the same way as in Oman. The training sessions were concerned with procedural knowledge on how to do the job. The ST inpatriates learned from the subject matter coaching so as to carry the knowledge to their native land.

"We have a short- term policy, through the standard operating procedures... they get the coaching, and then we check whether they are doing the job right." (HQ senior technical engineer).

Moreover, axiomatic knowledge is also transferred by the trainers and coaches concerning the organisation, business, values, expected behaviors, and norms.

"In (company A) we have values and a mindset to give them (ST inpatriates) and they really communicate both of these very well here in (company A). And you can really touch on them when actual things happen. So, I want to give an example, for example, we have a new system that's called Energize in (company A), where you can send a "Thank You" letter to someone through a portal, or you can also do more than that and send different rewards to him in points, and those points can later be translated into different rewards." (HQ VP top senior engineer)

Also, the ST assignment assisted inpatriates at HQ in fostering better professional relationships with HQ staff. To build relational knowledge, they must deal with a contact at HQ when they encounter a critical situation to enable work at the foreign subsidiary after the ST inpatriation duration.

"Today, if the ST have questions, they can post the question in the portal, or call the $H Q$, 
since they've already had contact with them." (LT expatriate-senior manager)

Typically, the inpatriation program is used by the organisational unit to transfer various types of knowledge to ST inpatriates to develop high levels of business expertise and strategic awareness among their international workforce to facilitate coordination and maintain a competitive edge across the globe (Harzing et al., 2016). For example, new engineer recruits in the Oman subsidiary were not given the opportunity for LT assignments at HQ because of cost reductions at HQ, so they sent them as ST inpatriates and expected them to use their new knowledge in their daily job and transfer it to their $\mathrm{HCN}$ follow workers.

"The Omani engineers sent for short-term assignment; we were expected to teach the new junior engineers at the challenge programme... we prepare them to be a leader here in Oman, to know how to coach, to give feedback and recruit engineers." (LT expatriate manager)

During the second stage of interviews in August- 2019, the researcher noted former ST inpatriates sitting next to junior recruits in the UK to transfer their expertise and knowledge obtained during their inpatriation at HQ.

"During the ST in UK, we learn to improve and do things differently to be more effective. Further, to understand what they are doing and why. Actually, I would like to know the risk behind that..." (ST inpatriate middle manager engineer)

"Recently, we trained the local engineers at Oman because it is perfect for UK engineers, they can motivate them and reduce the cost to the company for hiring expatriates..." (St inpatriate senior engineer).

Additionally, axiomatic knowledge can be transferred by the inpatriation program from the Oman subsidiary to HQ. ST inpatriates during the post to HQ helped to understand the values and habits of Omani peer.

"For example, this guy from Wales, has to work with the team in Oman...now he can see what happens in the work environment and can be there for those people, in the culture. Dealing with the different people from different cultures there. He then transfers that knowledge to Wales..." (ST inpatriate)

Lastly, inpatriates when they returned home could transfer procedural knowledge back to HQ. They improved daily tasks by continuing commitment and efficient standard operating processes, demonstrated their engagement to improve tasks and updated the operating processes (SOPs).

"Our staff realizes that to update themselves with new technology and the new things done at $H Q$, they need a certain level of knowledge. We are always encouraged to continuously improve and adopt new ideas or new ways of working in the SOPS..." (ST inpatriates)

Through the duration of their time in the HQ, the junior engineers asked former inpatriates to transfer knowledge, but the relationship of the junior engineers at the HQ did not have much effect because the inpatriation programme interactions for transferring relational and axiomatic knowledge ended. 
"No more reacting with the junior engineers on both sides, you know, engaging the others. Maybe you cannot find the people from the mission, like Oman." (LT expatriate manager)

The suspension of the ST inpatriation programme thus impacted the bilateral transfer of knowledge among HQ headquarter and the subsidiary.

\subsection{Knowledge Transfer Through ST Expatriation}

The MNCs used the expatriation program, whereby some of the staff were sent to ancillaries for training for three months to transfer the knowledge as ST expatriates. Initiated during the inpatriation period, most of the transfer of knowledge was by the ST expatriates.

"The engineers sent as ST expatriates provide the most valuable information to the Omani in a short period of time." (ST expatriate from HQ)

ST expatriates were concerned with the former ST inpatriates' axiomatic knowledge. The company used an on-the-job training model, but in a detailed manner, using different methods of learning to deliver the concept.

"As ST expatriates we try to deliver our knowledge to HCNs in different ways to ensure that knowledge transfer has been done..." (ST expatriate from HQ)

The finding indicated that the short-term expatriation assignment was crucial to transfer knowledge reverse home from the HQ in UK by inpatriates. For procedural knowledge, however, this happened formally through documents, for example, the Standard Operating Procedures. Therefore, the knowledge can be updated from the new junior engineers from HCNs, and ST expatriates.

"As you may hear in Oman, you know when you get someone like fresh off ... Or, as soon as the company can see it, taking the latest things from engineers, from the data in university to the work environment. They have valuable knowledge and discover new areas for procedural improvements." (ST expatriate)

Additionally, the junior engineers (former ST inpatriates) come back with new ideas they learned about practices used in HQ. After returning home to Oman they update and align their practices with $\mathrm{HQ}$.

"The junior engineers enhanced the way we coach in Oman, as will benefit all the engineers" (HQ-middle manager)

Moreover, the ST expatriates played a serious and clarity role in values and culture. This is a crucial shape axiomatic knowledge. Former ST expatriates transferred this knowledge to their $\mathrm{HCN}$ associates.

"Soft skills are important for former ST expatriates; they have to follow the regulations and responsibilities in the host country. So, like the holidays, locations, all the roles, the timing, the working hours, the days of work in the week, they have to follow these to avoid conflict between sites." (Middle-manager HQ)

\section{Discussion}


This research paper indicates that all the different assignments play important roles as knowledge transfer situations, yet not at the same time, and convey a type of knowledge. Furthermore, ST inpatriation is the utmost dynamic method to transfer various types of knowledge both through and following the assignment; and knowledge transfer from HQ to the subsidiary and the reverse are both considered to be important. Therefore, a portfolio of increasingly global international assignments is used (Collings and Isichei, 2017). The research paper contributed information about the role of international assignments in the headquarters and the subsidiary to transfer knowledge. The contribution and implications will be discussed in the next section.

\section{Implications for Theory}

Primarily, study has shown that international companies rely on relocations of staff among the HQ and subsidiary units with various types of assignment to transfer knowledge (Harzing, Pudelko \& Reiche, 2016, Reiche, 2011). However, none of the past research studies included IA in a single practical research design. This research paper provides evidence that the various types of IA sequel each other in regards conveying knowledge among the HQ and ancillaries. The finding discovered that changes in one IA have an impact on the efficacy of other international assignments in conveying knowledge, by concerning on the convey of various types of knowledge via different types of IA both in direction and timing. The current research provides unique insights into why a combination of IA international assignments is best, and not only a suitable combination is needed (Harzing et al., 2016) besides an appropriate arrangement of (IAs).

Within the case study company, the premise revolved around transmitting to inpatriates declarative and procedural knowledge about the processes and job descriptions. Yes, it was complicated to convey relational and axiomatic knowledge. The ST expatriation both validated and intensified the knowledge transfer when the inpatriates go back home. This arrangement was crucial, as after return to home in Oman former ST inpatriates begin doubting how to go about their functions more professionally. Therefore, deepening and strengthening of axiomatic knowledge by ST expatriation after the inpatriation assignment was found to be a strong mechanism. However, the LT expatriation program confirmed that HQ employees would be available on a daily basis to address any doubts about the knowledge conveyed through inpatriation, and to strengthen and enhance axiomatic knowledge, especially about HQ culture. This special arrangement simplifies the effort of ST expatriates, due to both the knowledge conveyed to the host country at headquarters and the common trust generated by individual communications among HCNs and HQ employees through inpatriation (Harvey et al., 2011). In comparison, the junior engineers after the ST inpatriation program were unable to form any association with HQ employees due to limited development of trust (Kostova et al., 2003) and also to different procedures at the HQ. Consequently, lack of trust hindered the influence and transfer of knowledge at both HQ and the foreign subsidiary. Research has found that knowledge convey is not a 'once-and for-all' issue (Paulin et al., 2012). It requires strengthening and emphasis always and understanding the policy and roles within the host countries (Moeller \& Reiche, 2017). 
Additionally, the research provides novel insights in the internationality of some knowledge convey among the (HQ) headquarter and foreign unit relations. For example, in the case study the ST inpatriation assignment was launched to convey relational knowledge; however, this can later be instrumental for the HCNs job as they are well-acquainted with the right point of contacts at HQ when they need assistance. The intent of the ST inpatriation program was to convey knowledge from HQ to the foreign subsidiary, such as in which way to do their work and how to do it, i.e. procedural and declarative knowledge. Along the same lines, headquarters can save cost with the ST expatriation program owing to its brief nature and can transfer important knowledge. Indeed, mixed assignments enable the HQ to know more about foreign subsidiary knowledge. Furthermore, this inadvertent knowledge flow proved challenging to the work of foreign subsidiary staff, due to communication among the two parties and enhancement of HQ practices grounded on the involvement of pervious inpatriates. However, great knowledge transfer might have disadvantages when HQ managers change the mix of IA used, without recognizing the great role played by various types of assignments in transferring knowledge to and from the foreign ancillaries. Also, the study added an immediate knowledge transfer component (Kogut \& Zander, 1993) via an ST inpatriation program, which is particularly crucial for the convey of relational and axiomatic knowledge by both the HQ and ancillaries.

\section{Implications for Practice}

For the distribution, creation, and sharing of knowledge to be an effective process, in-depth connection, twofold criticism loops and continuing unofficial discussion are needed. The study observed that organisations must take into consideration a portfolio of varied IA types for knowledge convey from and to HQ. Thus, MNCs should consider whether each IA type is especially appropriate to pass on precise types of knowledge at various times, and the organisation should count them as integral expositions instead of replacements. For all the reasons described the portfolio of various types of IA must be carefully selected congruent to the firm's particular knowledge transfer requirements.

The study shows that, when proposing international assignments and in adjusting the assignments involved, it is crucial for headquarters' international HR or the team leadership to understand the various assignment roles in transferring knowledge from and to the ancillaries, and utilize the assignments due to different legislation in the HCNs. In present studies, In present studies, indicated that how the different assignments enhance each other, but inpatriation program was underestimated by headquarters. The resulting outcome was that they did not expect the effect of cut off the inpatriation assignments, and no drain was taken to make up for the absence of knowledge nor to relieve the peril of increasing dissension among the areas. This implies that team leaders are required to take special care so that knowledge transfer streams may take place.

One crucial case of combining knowledge transfer types is the extension of the firm's units of organization in foreign markets. The evolutionary procedure of an organization's expansion often proceeds by the setting up of facilities abroad for all the operational units. The inceptive entries thus play the role of a program that mixes the firm's knowledge obtained in its parent 
company market with the gradual gathering of learning in the foreign market. In the culminative part of this process, the learning from the international market is transferred globally and impacts the accumulation and refiguration of knowledge during the communication among ancillaries, including the headquarters market.

Likewise, the employees chosen for international assignments must be appropriate for the purpose of assignment, and realizing the particular roles of various international assignment types will assist the organization in choosing the potential employees, with specific skillsets to counter the challenge of conveying knowledge abroad.

\section{Future Research Suggestion and Limitations}

In spite the vital contributions of this study, it has some limitations. Firstly, the study focused on a global Oil and Gas company, in two countries, UK and Oman, which hinders the abstraction of the study results. However, the qualitative method can be extended to various types of assignments, from the perspective of professional engineers in both parties. Also, it might open the door to more country and sector-wise frame of references, which can provide more information and knowledge through different types of international assignments used to transfer knowledge at diverse phases.

\section{Conclusion}

The research conducted interviews with 20 professional engineers in two countries, in the UK headquarters and Oman subsidiary of a global Oil and Gas MNC. The research was a probe into the range to which various types of IA relay various types of knowledge. We explored LT expatriation, ST expatriation, and inpatriation IA to simplify relaying various types of knowledge in various ways and at various instances. This distinction enhances the knowledge transfer procedure and might transcend into additional efficacious knowledge transfer among headquarters and foreign ancillaries.

The findings of the study, therefore, strengthen the rationalization that depending on expatriation as a rule with international employees is in a positive light sufficient, and potentially hurtful worst-case scenario potentially detrimental (Harzing et al., 2016); they illustrate how the combination of international assignment types and the arrangement of international assignments is another challenging component in operational HQ-foreign ancillary knowledge transfer.

\section{Acknowledgments}

I want to share my thanks to the number of people who contributed to my study. First, I extend my gratitude to the participants of this study who were interested in taking apart and sharing their experiences with me. Their truthful contributions and honesty are the basis of this research, and I am grateful to them for sharing their accounts. Second, I wish to thank my two supervisors who have been an incredible source of support. They have provided a visionary critique from both the research method, and subject-specific perspectives, and their expertise has proved crucial. 


\section{References}

Al Ariss, A., Cascio, W. F., \& Paauwe, J. (2014). Talent management: Current theories and future research directions. Journal of World Business, 49(2), 173-179. https://doi.org/10.1016/j.jwb.2013.11.001

Anderson, J. R. (1976). Language, memory, and thought. Lawrence Erlbaum.

Anderson, J. R. (1995). Cognitive psychology and its implications, 4th edition. W.H. Freeman and Company: New York.

Antal, A. B. (2000). Types of knowledge gained by expatriate managers. Journal of General Management, 26(2), 32-51. https://doi.org/10.1177/030630700002600203

Barner-Rasmussen, W., Ehrnrooth, M., Koveshnikov, A., \& Makela, K. (2014). Cultural and language skills as resources for boundary spanning within the MNC. Journal of International Business Studies, 45(7), 886-905. https://doi.org/10.1057/jibs.2014.7

Black, J. S., Gregersen, H. B., \& Mendenhall, M. E. (1992). Global Assignments. San Francisco, CA: Jossey-Bass.

Bonache, J., \& Brewster, C. (2001). Knowledge transfer and the management of expatriation. Thunderbird International Business Review, 43(1), 145-168. https://doi.org/10.1002/1520-6874(200101/02)43:1<145::AID-TIE9>3.0.CO;2-7

Brewster, C., \& Suutari, V. (2005). Global HRM: aspects of a research agenda. Personnel Review, 34(1), 5-21. https://doi.org/10.1108/00483480510571851

Cao, J., Pan, X., \& Tian, G. (2012). Disproportional ownership structure and pay-performance relationship: Evidence from China's listed firms. Journal of Corporate Finance, 17(3), 541-54. https://doi.org/10.1016/j.jcorpfin.2011.02.006

Chang, Y.-Y., Gong, Y., \& Peng, M. W. (2012). Expatriate knowledge transfer, subsidiary absorptive capacity, and subsidiary performance. Academy of Management Journal, 55(2), 927-948. https://doi.org/10.5465/amj.2010.0985

Choi, S. G., \& Johanson, J. (2012). Knowledge translation through expatriates in international knowledge transfer. International Business Review, 21(2012), 1148-1157. https://doi.org/10.1016/j.ibusrev.2012.01.002

Cohen, W. M., \& Levinthal, D. A. (1990). Absorptive capacity: A new perspective on learning and innovation. Administrative Science Quarterly, 35(1), 128-152. https://doi.org/10.2307/2393553

Collings, D. G., \& Isichei, M. (2017). The shifting boundaries of global staffing: Integrating global talent management, alternative forms of international assignments and nonemployees into the discussion. The International Journal of Human Resource Management, 29(1), 165-187. https://doi.org/10.1080/09585192.2017.1380064

Collings, D. G., McDonnell, A., Gunnigle, P., \& Lavelle, J. (2010). Swimming against the 
tide: Outward staffing flows from multinational subsidiaries. Human Resource Management. https://doi.org/10.1002/hrm.20374

Duviviera, F., Peetersb, C., Harzing, A. W. (2019). Not all international assignments are created equal: HQ-subsidiary knowledge transfer patterns across types of assignments and types of knowledge. Journal of World Business. https://doi.org/10.1016/j.jwb.2019.02.003

Edström, A., \& Galbraith, J. R. (1977). Transfer of managers as a control and coordination strategy in multinational organizations. Administrative Science Quarterly, 22(2), 248-263. https://doi.org/10.2307/2391959

Edström, A., \& Galbraith, J. R. (1977a). Transfer of managers as a control and coordination strategy in multinational organizations. Administrative Science Quarterly, 22(June), 11-22. https://doi.org/10.2307/2391959

Edström, A., \& Galbraith, J. R. (1977b). Alternative policies for international transfers of managers. Management International Review, 17(2), 11-22 (also reprinted in 34(1), special issue, p.71-82).

Fang, R., Jiang, G.-L. F., Makino, S., \& Beamish, P. W. (2010). Multinational firm knowledge, use of expatriates, and foreign subsidiary performance. Journal of Management Studies, 47(1), 27-54. https://doi.org/10.1111/j.1467-6486.2009.00850.x

Groutsis, D., \& Arnold, P. C. (2012). Tracking the career decisions and experience of migrant elites: The case of South African-trained medical professionals in the Australian labour market, Health Sociology Review, 21(3), 332-42. https://doi.org/10.5172/hesr.2012.21.3.332

Harvey, M. G., Speier, C., \& Novicevic, M. M. (2000). Strategic global human resource management. The role of inpatriate managers. Human Resource Management Review, 10(2), 153-75. https://doi.org/10.1016/S1053-4822(99)00044-3

Harvey, M., Reiche, B. S., \& Moeller, M. (2011). Developing effective global relationships through staffing with inpatriate managers: The role of interpersonal trust. Journal of International Management, 17(2), 150-161. https://doi.org/10.1016/j.intman.2011.01.002

Harvey, M., Speier, C., \& Novicevic, M. (1999). The role of inpatriation in global staffing. International Journal of Human Resource Management, 10(3), 459-476. https://doi.org/10.1080/095851999340422

Harzing, A. W. (2001a). Of bears bees and spiders: The role of expatriates in controlling foreign subsidiaries. Journal of World Business, 36(4), 366-379. https://doi.org/10.1016/S1090-9516(01)00061-X

Harzing, A. W. (2001b). An analysis of the functions of international transfer of managers in MNCs. Employee Relations, 23(6), 581-598. https://doi.org/10.1108/01425450110409248

Harzing, A. W. (2004). Composing and international staff. In Harzing, A. W., \& van Ruysseveldt, J. (eds), International human resource management (pp. 251-282), (2 ${ }^{\text {nd }}$ ed.). London: Sage. 
Harzing, A. W., Pudelko, M., \& Sebastian Reiche, B. S. (2016). The bridging role of expatriates and inpatriates in knowledge transfer in multinational corporations. Human Resource Management, 55(4), 679-695. https://doi.org/10.1002/hrm.21681

Haslberger, A., Brewster, C., \& Hippler, T. (2014). Managing performance abroad: A new model for understanding expatriate adjustment. Routledge. https://doi.org/10.4324/9780203111468

Hocking, J. B., Brown, M. E., \& Harzing, A. W. (2007). Balancing global and local strategic contexts: Expatriate knowledge transfer, applications and learning within a transnational organization. Human Resource Management, 46(4), 513-533. https://doi.org/10.1002/hrm.20180

Hocking, J. B., Brown, M., \& Harzing, A. W. (2004). A knowledge transfer perspective of strategic assignment purposes and their path-dependent outcomes. The International Journal of Human Resource Management, 15(3), 565-586. https://doi.org/10.1080/0958519042000181269

Kogut, B., \& Zander, U. (1993). Knowledge of the firm and the evolutionary theory of the multinational corporation. Journal of International Business Studies, 24(4), 625-645. https://doi.org/10.1057/palgrave.jibs.8490248

Kostova, T., \& Roth, K. (2003). Social capital in multinational corporations and a micro macro model of its formation. Academy of Management Review journal, 28(2), 297-317. https://doi.org/10.5465/amr.2003.9416356

Kühlmann, T., \& Hutchings, K. (2010). Expatriate assignments vs localization of management in China: Staffing choices of Australian and German companies. Career Development International, 15(1), 20-38. https://doi.org/10.1108/13620431011020871

Kumar, J., \& Ganesh, L. S. (2009). Research on knowledge transfer in organizations: A morphology. Journal of Knowledge Management, 13(4), 161-174. https://doi.org/10.1108/13673270910971905

Lagerström, K., \& Andersson, M. (2003). Creating and sharing knowledge within a transnational team-The development of a global business system. Journal of World Business, 38(2), 84-95. https://doi.org/10.1016/S1090-9516(03)00003-8

Lazarova, M., \& Tarique, I. (2005). Knowledge transfer upon repatriation. Journal of World Business, 40(4), 361-373. https://doi.org/10.1016/j.jwb.2005.08.004

Mäkelä, K. (2007). Knowledge sharing through expatriate relationships: A social capital perspective. International Studies of Management \& Organization, 37(3), 108-125. https://doi.org/10.2753/IMO0020-8825370305

Mäkelä, K., \& Brewster, C. (2009). Interunit interaction contexts, interpersonal social capital, and the differing levels of knowledge sharing. Human Resource Management journal, 48(4), 591-613. https://doi.org/10.1002/hrm.20300 
McNulty, Y. (2016). Why expatriate compensation will change how we think about global talent management. Global talent management and staffing in MNEs. Emerald Group Publishing Limited125-150. https://doi.org/10.1108/S1876-066X20160000032005

McNulty, Y., \& Brewster, C. (2017). Theorizing the meaning (s) of 'expatriate': Establishing boundary conditions for business expatriates. The International Journal of Human Resource Management, 28(1), 27-61. https://doi.org/10.1080/09585192.2016.1243567

McNulty, Y., \& Brewster, C. (2017). Theorizing the meaning (s) of 'expatriate': Establishing boundary conditions for business expatriates. The International Journal of Human Resource Management, 28(1), 27-61. https://doi.org/10.1080/09585192.2016.1243567

Miles, M. B., \& Huberman, A. M. (1994). Qualitative data analysis: A sourcebook. Beverly Hills: Sage Publications.

Mockaitis, A. I., Zander, L., \& De Cieri, H. (2018). 'The benefits of global teams for international organizations: HR implications. The International Journal of Human Resource Management, 18(1), 1-22. https://doi.org/10.1080/09585192.2018.1428722

Moeller, M., \& Reiche, B. S. (2017). Inpatriates. A review, synthesis and outlook of two decades of research. In Y. McNulty and J. Selmer (eds), Research Handbook of Expatriates (pp. 218-240). USA: Edward Plgar https://doi.org/10.4337/9781784718183.00021

Moeller, M., Harvey, M. G., \& Williams, W. A. (2010). Socialization of inpatriate managers to the headquarters of global organizations. A social learning perspective. Human Resource Development Review, 9(2), 169-93. https://doi.org/10.1177/1534484310361917

Moeller, M., Maley, J., Harvey, M., \& Kiessling, T. (2015). Global talent management and inpatriate social capital building: a status inconsistency perspective, The International Journal of Human Resource Management, 27(9), 991-1012. https://doi.org/10.1080/09585192.2015.1052086

Neff, K., D., \& Seppala, E. (2012). Compassion, Well-Being, and the Hypoegoic Self. In K. W. Brown \& M. Leary (Eds), Oxford Handbook of Hypo-egoic Phenomena: Theory and Research on the Quiet Ego. Oxford University Press.

Nonaka, I. (1994). A dynamic theory of organizational knowledge creation. Organization Science, 5(1), 14-37. https://doi.org/10.1287/orsc.5.1.14

Nonaka, I., \& Takeuchi, H. (1995). The knowledge-creating company: How Japanese companies create the dynamics of innovation (pp. 663-673). Oxford University Press.

Ohlsson, S. (1993). The interaction between knowledge and practice in the acquisition of cognitive skills. In S. Chipman \& A. L. Meyrowitz (Eds.), Foundations of knowledge acquisition: Cognitive models of complex learning (pp. 147-208). Boston: Kluwer. https://doi.org/10.1007/978-1-4615-3172-2_5

Ohlsson, S. (1996). Learning from performance errors. Psychological Review, 103(2), 
241-262. https://doi.org/10.1037/0033-295X.103.2.241

Paulin, D., \& Suneson, K. (2012). Knowledge transfer, knowledge sharing and knowledge barriers-three blurry terms in KM. The Electronic Journal of Knowledge Management, 10(1), 81-91.

Pinto, L. H., Cabral-Cardoso, \& Werther, W. B. (2012). Compelled to go abroad: motives and outcomes of international assignments, International assignments, International Journal of Human Resource Management, 23(11), 2295-313. https://doi.org/10.1080/09585192.2011.610951

Reiche, B. S. (2006). The inpatriate experience in multinational corporations: An exploratory case study in Germany. International Journal of Human Resource Management, 17(9), 1572-1590. https://doi.org/10.1080/09585190600878386

Reiche, B. S. (2011). Knowledge transfer in multinationals: The role of inpatriates' boundary spanning. Human Resource Management, 50(3), 365-389. https://doi.org/10.1002/hrm.20423

Reiche, B. S. (2012). Knowledge benefits of social capital upon repatriation: A longitudinal study of international assignees. Journal of Management Studies, 49(6), 1052-1077. https://doi.org/10.1111/j.1467-6486.2012.01050.x

Reiche, B. S., Harzing, A. W., \& Kraimer, M. L. (2009). The role of international assignees' social capital in creating inter-unit intellectual capital: A cross-level model. Journal of International Business Studies, 40(2009), 509-526. https://doi.org/10.1057/jibs.2008.86

Reiche, B. S., Kraimer, M. L., \& Harzing, A. W. (2011). Why do international assignees stay? An organizational embeddedness perspective. Journal of International Business Studies, 42(4), 521-544. https://doi.org/10.1057/jibs.2011.5

Sackmann, S. A. (1992). Culture and subcultures: An analysis of organizational knowledge. Administrative Science Quarterly, 27(3), 140-161. https://doi.org/10.2307/2393536

Salamin, X., \& Hanappi, D. (2014). "Women and international assignments", Journal of Global Mobility, 2(3), 343 - 374. https://doi.org/10.1108/JGM-09-2013-0058

Salleh, N. M., \& Koh, J. (2013). Analysing the functions of short-term expatriate assignments. Procedia-Social and Behavioral Sciences, 107(2013), 34-42. https://doi.org/10.1016/j.sbspro.2013.12.396

Salleh, N. M., \& Nankervis, A. (2015). Non-traditional expatriate assignments in the AsiaPacific: Characteristics \& challenges. Human Resource Management Research, 5(1), 1-11. https://doi.org/10.1016/B978-0-08-100643-6.00001-4

Sanchez, R., \& Heene, A. (1996). Strategic learning and knowledge management. New York, NY: John Wiley \& Sons.

Schuler, R. S., Dowling, P. J., \& De Cieri, H. (1993). An integrative framework of strategic international human resource management. Journal of Management, 19(2), 419-459. https://doi.org/10.1177/014920639301900209 


\section{Macrothink}

International Journal of Human Resource Studies

ISSN 2162-3058

2020, Vol. 10, No. 4

Sedlmayer, S. (2009). Expatriates-Eine kritische Betrachtung aus organisationaler Perspektive (Doctoral dissertation, Thesis at Universitates der Bundeswehr Muenchen).

Shaffer, M. A., \& Harrison, D. A. (1998). Expatriates' psychological withdrawal from international assignments: Work, nonwork, and family influences. Personnel Psychology, 51(1), 87-118. https://doi.org/10.1111/j.1744-6570.1998.tb00717.x

Squire, L. R. (1987). Memory and Brain. Oxford University Press, Oxford.

Suutari, V., Brewster, C., Riusala, K., \& Syrjäkari, S. (2013). Managing non-standard international experience: Evidence from a Finnish company. Journal of Global Mobility, 1(2), 118-138. https://doi.org/10.1108/JGM-10-2012-0014

Szulanski, G. (2000). The process of knowledge transfer: A diachronic analysis of stickiness. Organizational Behavior and Human Decision Processes, 82(1), 9-27. https://doi.org/10.1006/obhd.2000.2884

Szulanski, G., Cappetta, R., \& Jensen, R. J. (2004). When and how trustworthiness matters: Knowledge transfer and the moderating effect of causal ambiguity. Organization Science, 15(5), 600-613. https://doi.org/10.1287/orsc.1040.0096

Tahvanainen, M., Welch, D., \& Worm, V. (2005). Implications of short-term international assignments. European Management Journal, 23(6), 663-673. https://doi.org/10.1016/j.emj.2005.10.011

Winograd, T. (1975). Computer memories: A metaphor for memory organization. In C.N. Cofer (Ed.), The structure of human memory (pp. 133-161). San Francisco: Freeman.

Yin, R. K. (2009). Case study research: Design and methods, Vol. 5. London: Sage Publications.

Zaheer, S. (1995). Overcoming the liability of foreignness. Academy of Management Journal, 38(2), 341-363. https://doi.org/10.2307/256683

\section{Copyright Disclaimer}

Copyright for this article is retained by the author(s), with first publication rights granted to the journal.

This is an open-access article distributed under the terms and conditions of the Creative Commons Attribution license (http://creativecommons.org/licenses/by/4.0/). 